\title{
MICROSTRUCTURE AND TEXTURE OF A WARMED ROLLED IF STEEL
}

\author{
C. S. DA COSTA VIANA*, J. R. G. MATHEUS, \\ A. M. LOPES and H. H. ALY EL-SHARAWY \\ Department of Mechanical and Materials Engineering, \\ Military Institute of Engineering, 22290-270, Rio de Janeiro, RJ, Brazil
}

(Received 25 April 2000)

\begin{abstract}
Steel rolling within the temperature range intermediate between hot and cold rolling represents today a very economical and technically viable operation. The present work investigates the microstructure and the texture developed in a Ti microalloyed IF steel by rolling at $400^{\circ} \mathrm{C}$ and $600^{\circ} \mathrm{C}$. Reductions of $40 \%$ and $60 \%$ were applied to a set of as hot rolled strip specimens part of which was subsequently annealed at $800^{\circ} \mathrm{C}$ for 5 minutes. Both the microstructure and the texture were examined by scanning electron microscopy. The texture was analysed by Electron Back Scattering Diffraction (EBSD) and Orientation Image Microscopy (OIM), and represented via the ODF method. The plastic anisotropy was also characterised. It was found that the textures developed by warm rolling are similar to those obtained by cold rolling, the intensities being also of comparable value. The microstructure is characterised by the presence of many shear banded grains whose amount was also quantified.
\end{abstract}

Keywords: Texture; Warm rolling; EBSD; Formability

\section{INTRODUCTION}

Rolling is the most frequently used method of metal processing its main characteristics being high productivity and considerable dimensional precision. In this process, the metal is subject to high compressive stresses, as a result of which both texture and microstructure are quickly developed.

\footnotetext{
${ }^{*}$ Corresponding author.
} 
The rolling operation may be performed at relatively high temperatures or at room temperature (cold rolling). During hot rolling, the steel plates are heated between $1100^{\circ} \mathrm{C}$ and $1300^{\circ} \mathrm{C}$. The final rolling passes are performed between $900^{\circ} \mathrm{C}$ and $700^{\circ} \mathrm{C}$ and the strip is coiled immediately after. When the hot coil cools down to room temperature, the material is ready for the cold rolling process.

In the case of the IF steels, in which the $\mathrm{C}$ and $\mathrm{N}$ contents are smaller than $50 \mathrm{ppm}$, hot rolling may finish either in the austenite or in the ferrite region. When hot rolling is finished in the austenite region, the texture of the strip is generally weak (close to random). However, when rolling is finished within the ferrite region, a strong $\{111\}\langle\mathrm{uvw}\rangle$ fiber texture may be obtained. These components are responsible for the excellent drawability of the steels.

Currently, the steel industries are greatly interested in warm rolling due to the better properties and lower cost of the finished product. Steel working within the range intermediate between hot and cold rolling represents a more economical operation, having that hot rolling implies considerably higher costs in order to conserve the high temperature. Also, in cold rolling, the working loads and roll wear are high, which also reflect in high costs. Besides, the holding time required for the hot strip to cool down to room temperature before cold rolling is also reduced.

According to Harlet et al. (1993), a reduction of $200^{\circ} \mathrm{C}$ to $300^{\circ} \mathrm{C}$ in the slab reheating temperature, which is possible when rolling the IF steels within the ferrite range, implies a significant reduction of costs.

This paper aims at characterising the texture and microstructure of an IF steel warm rolled at $400^{\circ} \mathrm{C}$ and $600^{\circ} \mathrm{C}$. Additionally, the potential for recrystallisation of these materials and the resulting plastic anisotropy are investigated.

\section{EXPERIMENTAL}

The steel used in this work was a Titanium IF steel supplied in the form of hot rolled strips, $3.64 \mathrm{~mm}$ thick, with the nominal chemical composition shown in Table I.

Warm rolling reductions of $40 \%$ and $60 \%$ were applied to $100 \mathrm{~mm}$ square strip samples at $400^{\circ} \mathrm{C}$ and $600^{\circ} \mathrm{C}$. Part of this material was 
TABLE I Chemical composition of the I.F.-Ti steel

\begin{tabular}{lcccccccc}
\hline$C$ & $A l$ & $T i$ & $M n$ & $N i$ & $P$ & $N$ & $S$ & $N b$ \\
\hline 0.003 & 0.052 & 0.075 & 0.18 & 0.006 & 0.017 & 0.0047 & 0.007 & 0.002 \\
\hline
\end{tabular}

subsequently annealed at $800^{\circ} \mathrm{C}$ for 5 minutes. $60 \%$ reduction is the limit imposed by the need to obtain distinguishable Kikuchi patterns in the EBSD analysis used here for texture measurement. The patterns would be indistinguishable under the $85 \%$ reduction normally used in industry. A separate specimen was $60 \%$ cold rolled and annealed at $800^{\circ} \mathrm{C}$ for 5 minutes. The data obtained from the latter formed a reference set for the other treatment conditions.

A two-high laboratory mill was used for rolling the specimens while maintaining their original rolling direction. All the reheating and annealing treatments were done in a muffle type furnace. The specimens were sectioned along the rolling direction and the sectioned surfaces were polished using a $1 \mu \mathrm{m}$ grit diamond paste followed by electrolytic polishing. The samples were initially observed under the optical microscope in order to measure their mean grain sizes, according to the ASTM E112 standard. This grain size was a guide for the determination of the scanning step in the EBSD analysis. The latter was always taken as smaller than about $50 \%$ of the mean grain size so that, on average, at least one pattern per grain was obtained.

Texture measurement was performed in a scanning electron microscope using the EBSD technique. The resulting data were analysed using the OIM method to process and index the Kikuchi patterns automatically. The orientation distribution function (ODF) was calculated by fitting a Bunge (1965) type Gauss function series to the data. This is necessary for the characterization of the textures and calculation of the mechanical and forming properties. Property prediction was done by means of the computer programmes available in the laboratory.

Generally, scanning a single area by EBSD is usually not enough to cover a sufficient number of grains to obtain a representative ODF comparable to that obtained by X-ray diffraction. In this work at least 2300 grains were used per ODF analysis. This was the result of measuring up to ten areas, depending on the average grain size, and adding up the orientation data in a single file. The scanned areas were all located along the longitudinal midplane of the specimens 
(Matheus, 1999) to avoid misrepresentation of the specimen texture, due to texture gradient through the thickness.

\section{RESULTS AND DISCUSSION}

The microstructures of the specimens rolled at $400^{\circ} \mathrm{C}$ and $600^{\circ} \mathrm{C}$ are shown in Figure 1. It can be seen that they are characteristic of steels deformed within the ferrite range, containing elongated grains and a distribution of in-grain shear bands. The percentages of shear banded grains are shown in Figure 2. This figure shows that the percentage increases with both deformation and deformation temperature. This fact had also been observed by Barnett and Jonas (1997), for a similar material, with respect to the temperature dependence only.

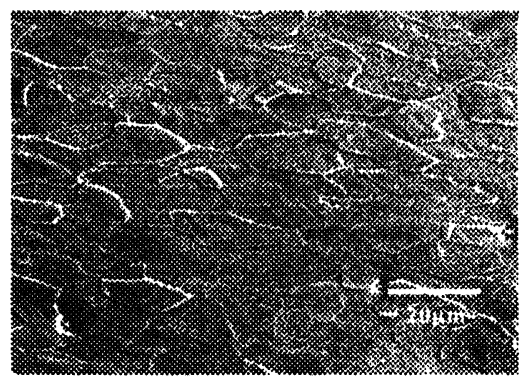

(a)

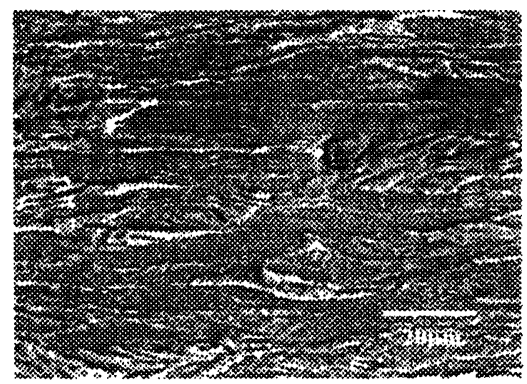

(c)

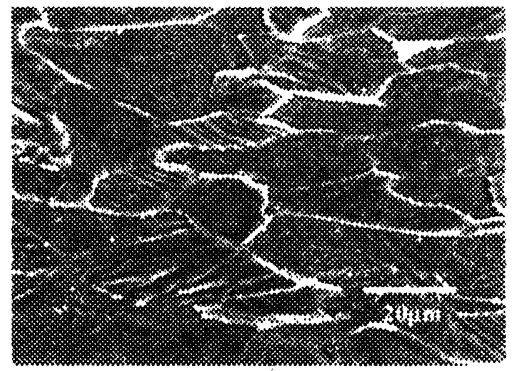

(b)

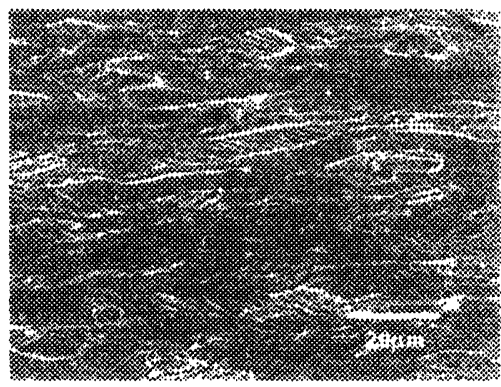

(d)

FIGURE 1 Elongated grains: $40 \%$ rolling: (a) at $400^{\circ} \mathrm{C}$; (b) at $600^{\circ} \mathrm{C}$; $60 \%$ rolling: (c) at $400^{\circ} \mathrm{C}$; (d) at $600^{\circ} \mathrm{C}$. 


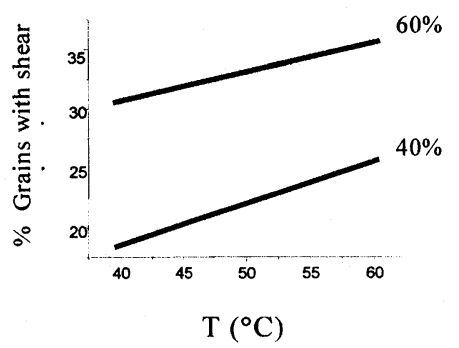

FIGURE 2a Percentage of shear banded grains as a function of the deformation temperature.

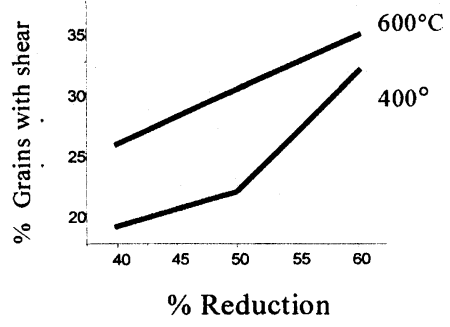

FIGURE 2b Percentage of shear banded grains as a function of rolling reduction.

Figure 3 shows the microstructures of the annealed specimens. Figure 3a shows the cold rolled material; (b) and (c) show the results for $40 \%$ and $60 \%$ warm rolling at $400{ }^{\circ} \mathrm{C}$ and (d) and (e), for $40 \%$ and $60 \%$ at $600^{\circ} \mathrm{C}$, respectively. All samples were annealed at $800^{\circ} \mathrm{C}$ for 5 minutes and air-cooled. The average grain sizes obtained were $19 \mu \mathrm{m}$, $13 \mu \mathrm{m}$ and $14 \mu \mathrm{m}$, for the microstructures shown in Figures 3(a), (c) and (e), respectively. These were the specimens that recrystallised. The $40 \%$ warm rolled specimens, shown in Figures 3(c) and (d), did not recrystallise.

The ODFs of the materials, shown in Figures 5 and 6, may be analysed using the diagram of Figure 4. This allows the proper identification of the orientations belonging in the $\mathrm{RD}$ and $\mathrm{TD}$ fibers.

The left-hand side of Figure 4 shows the components belonging in the RD fiber and the right hand side shows the components of the TD fiber. Figure 5 shows the textures of the materials warm rolled at $400^{\circ} \mathrm{C}$ and $600^{\circ} \mathrm{C}$. The main components are the $\{112\}\langle 110\rangle$, 


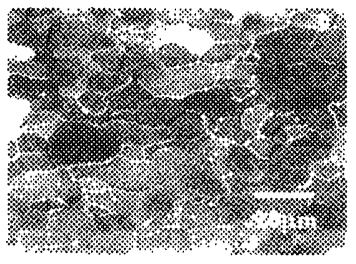

(a)

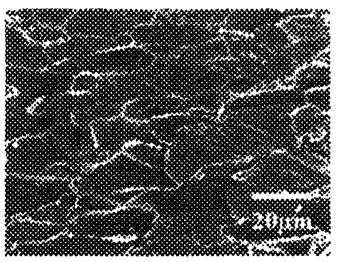

(b)

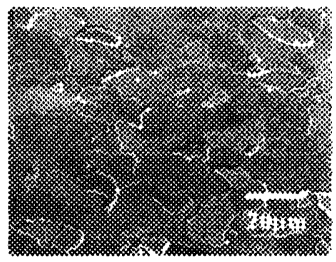

(c)

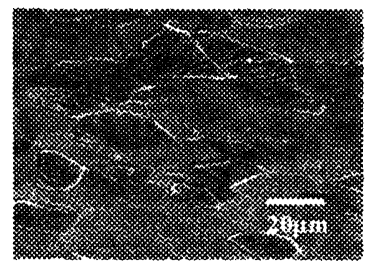

(d)

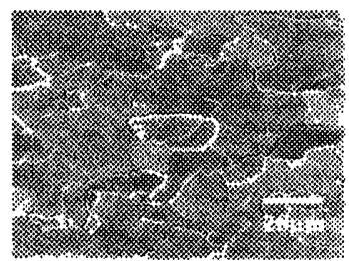

(e)

FIGURE 3 Microstructures of material: (a) $60 \%$ cold rolled; (b) $40 \%$ rolled at $400^{\circ} \mathrm{C}$; (c) $60 \%$ rolled at $400^{\circ} \mathrm{C}$; (d) $40 \%$ rolled at $600^{\circ} \mathrm{C}$; (e) $60 \%$ rolled at $600^{\circ} \mathrm{C}$; All annealed at $800^{\circ} \mathrm{C}$ for 5 minutes.

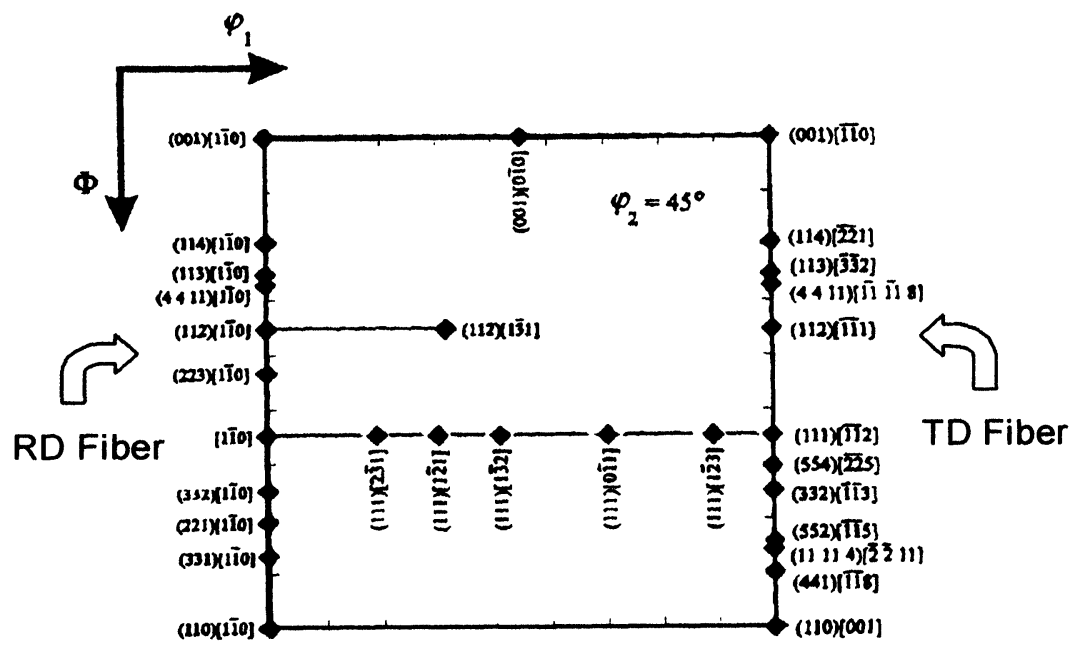

FIGURE $4 \varphi_{2}=45^{\circ}$ section in Bunge notation showing the main texture components and the RD and TD fibers. 


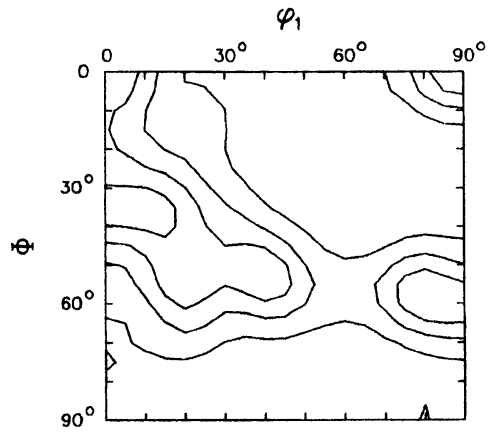

(a) 1 to 4

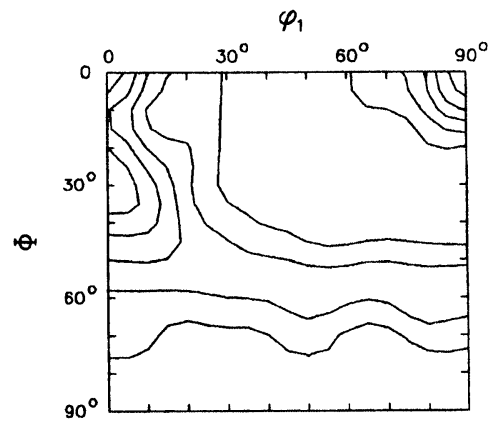

(c) 1 to 5

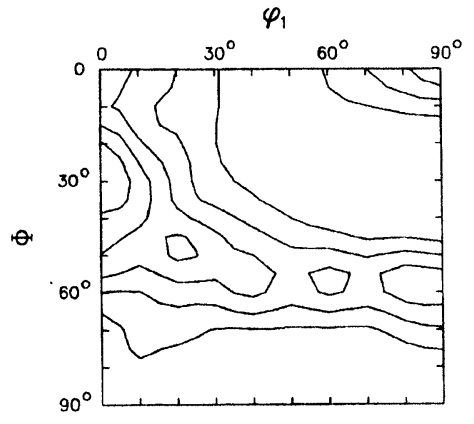

(b) 1 to 5

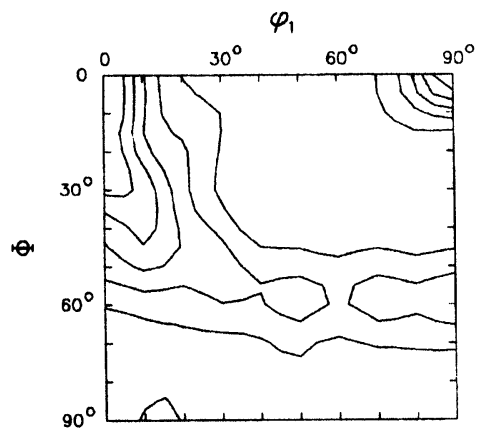

(d) 1 to 5

FIGURE 5 ODF of the $40 \%$ reduced samples at: (a) $400^{\circ} \mathrm{C}$, (b) $600^{\circ} \mathrm{C}$; ODF of the $60 \%$ reduced samples at: (c) $400^{\circ} \mathrm{C}$; (d) $600^{\circ} \mathrm{C}$. Contour values under figures.

$\{113\}\langle 110\rangle$ and $\{001\}\langle 110\rangle$. The latter is characteristic of steel deformation textures and, here, showed the highest intensity increase with increasing deformation (from about 3 to 5). In general, for the same reduction, the intensities differed only marginally as function of temperature.

A careful analysis of the RD and TD fibers of the deformed materials indicates that, for $60 \%$ reduction, the orientations are nearly the same and have approximately the same intensities for both $400^{\circ} \mathrm{C}$ 

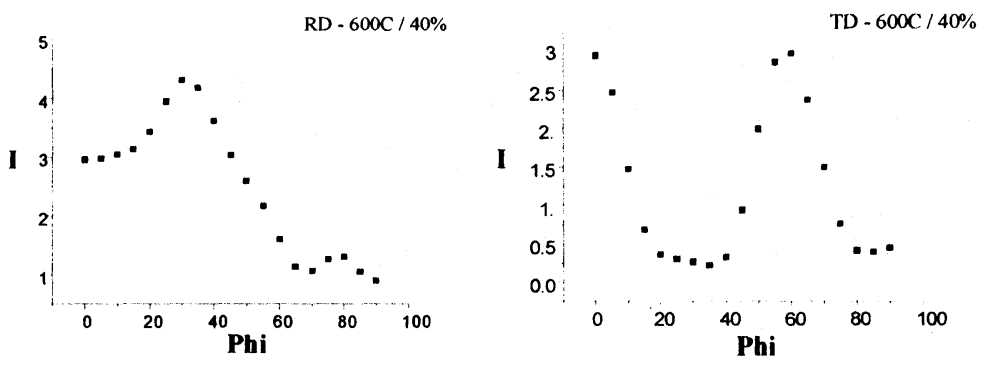

(a)
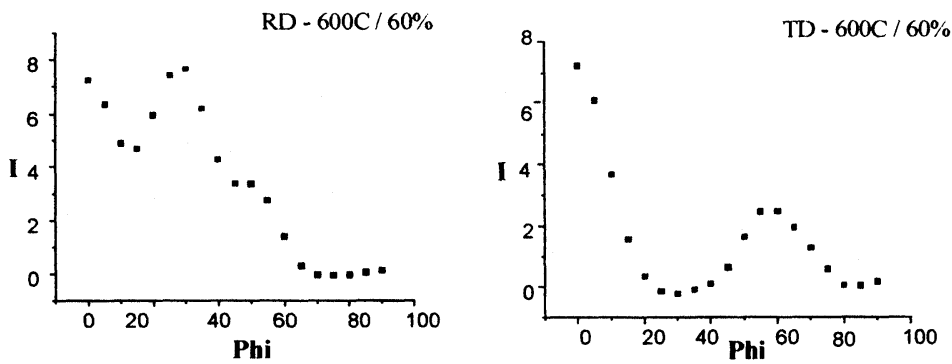

(b)

FIGURE 6 RD and TD fibers for the material rolled at $600^{\circ} \mathrm{C}$ : (a) $40 \%$ rolled; (b) $60 \%$ rolled.

and $600^{\circ} \mathrm{C}$. Figure 6 shows the two fibers for the material rolled at $600^{\circ} \mathrm{C}$. For $40 \%$ reduction, the peaks occur at about $5^{\circ}$ from $\{112\}\langle 110\rangle$, for the DL fiber, and $5^{\circ}$ from $\{111\}\langle 112\rangle$, for the DT fiber; the orientation $\{001\}\langle 110\rangle$ is also very intense. For $60 \%$, the peaks are on $\{001\}\langle 110\rangle$ and near $\{113\}\langle 110\rangle$, on the DL fiber, and on $\{001\}\langle 110\rangle$ and near $\{554\}\langle 225\rangle$, for the DT fiber. The texture components obtained for both $400^{\circ} \mathrm{C}$ and $600^{\circ} \mathrm{C}$ are typical of the textures observed for low carbon steel rolling textures; even the intensities are similar despite the unavoidable recovery effect introduced by the high deformation temperature.

In her cold rolling experiments, Avilla (1998) found peaks close to the $\{112\}\langle 1 \overline{1} 0\rangle$ and $\{223\}\langle 1 \overline{1} 0\rangle$ orientations, for the RD fiber, and the 


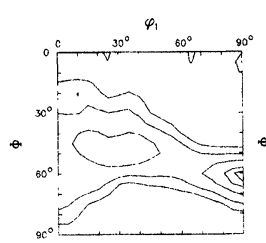

(a) $1,2,4,6,7$

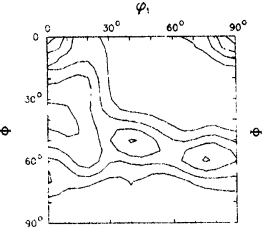

(b) 1 to 4

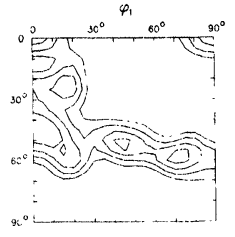

(c) 2 to 5

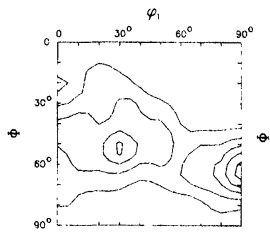

(d) 1 to 5

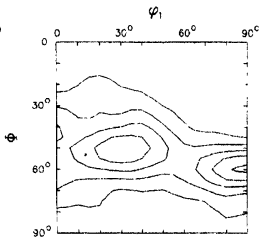

(e) 1 to 5

FIGURE 7 ODF (a) cold rolled and annealed, (b) $400^{\circ} \mathrm{C}, 40 \%$, annealed; (c) $600^{\circ} \mathrm{C}$, $40 \%$ and annealed; (d) $400^{\circ} \mathrm{C}, 60 \%$ and annealed; (e) $600{ }^{\circ} \mathrm{C}, 60 \%$ and annealed. Annealing: $800^{\circ} \mathrm{C}, 5 \mathrm{~min}$. Contour values under figures.

$\{554\}\langle\overline{2} \overline{2} 5\rangle$ orientation for the TD fiber. Likewise, when warm rolling IF steels, Barnett (1996) found maximum intensities at $\{111\}\langle 1 \overline{1} 0\rangle$, for the RD fiber, and at $\{554\}\langle\overline{2} \overline{2} 5\rangle$, for the TD fiber. The results of both authors are similar to those found in this paper.

Figure 7 shows the textures of the annealed specimens. The specimens in Figures $7 \mathrm{~b}$ and $7 \mathrm{c}$ did not recrystallise and, accordingly, they still display a strong $\{001\}\langle 110\rangle$ component. The main orientations of the recrystallised samples are the $\{111\}\langle 112\rangle$ and $\{332\}\langle 113\rangle$, the latter being the stronger one in all the textures. According to Daniel and Jonas (1990), strong $\{001\}\langle 110\rangle,\{223\}\langle 110\rangle,\{113\}\langle 110\rangle$ and $\{112\}\langle 110\rangle$ orientations in the material do not favour good drawability (high $R$-values). These orientations are not strong in the recrystallised samples and, consequently, satisfactory results were obtained for the predicted values of $R, \Delta R$ and $\bar{R}$ values, as will be seen below.

Only the $60 \%$ warm rolled materials were able to recrystallise under the annealing conditions used here. Apparently, the annealing out of defects of the $40 \%$ rolled materials reduced the initial energy available for recrystallisation. As can be seen, the textures of the recrystallised specimens bear strong similarities to that of the cold rolled and 


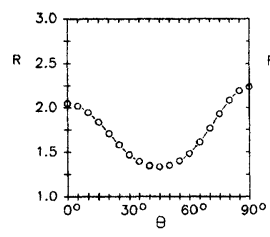

(a)

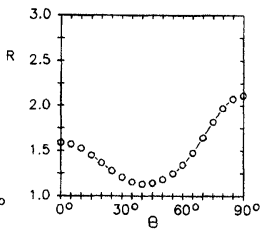

(b)

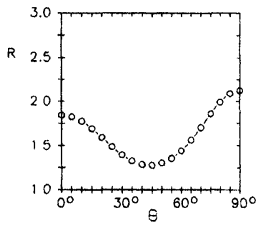

(c)

FIGURE 8 Angular variation of $R$ : (a) $60 \%$ cold rolled, $800^{\circ} \mathrm{C}, 5 \mathrm{~min}$; (b) $60 \%$ reduced at $400^{\circ} \mathrm{C}$, annealed; (c) $60 \%$ reduced at $600^{\circ} \mathrm{C}$, annealed.

annealed material. The same can be said with respect to the warm rolling textures.

Figure 8 shows the curves for the angular variation of the plastic anisotropy $(R)$ of the recrystallised specimens. It can be seen that $R$-values as high as 2.0 were obtained for $60 \%$ reduced materials, both warm and cold rolled.

The $\bar{R}$ and $\Delta R$ values obtained for the materials were $\bar{R}=1.74$ and $R=0.88 ; \bar{R}=1.50$ and $\Delta R=0.70 ; \bar{R}=1.63$ and $\Delta R=0.70$, respectively. The values predicted here for the $40 \%$ and $60 \%$ deformed specimens are well in agreement with those observed for cold rolled and annealed materials with the same reductions.

From the angular variation of the $R$-value a guess can be made of the ear profile in the Swift-cupping test. So, ears at $90^{\circ}$, in the RD and TD directions, should be expected for all the materials in Figure 8. This again shows that a plastic anisotropy similar to that induced by cold rolling is developed in ferrite rolled at warm temperatures. In general, the results obtained in this paper show that texture development in warm rolling IF steels are comparable to those found in the literature for cold rolled low carbon and IF steels.

\section{CONCLUSIONS}

The ODFs obtained in this work, using the sampling techniques described in the text, are of comparable quality to those obtained by $\mathrm{X}$-ray diffraction. This permitted deriving several important conclusions about the warm rolling of IF steels. The textures developed in $\mathrm{Ti}$ alloyed IF steels by $40 \%$ and $60 \%$ warm rolling at $400^{\circ} \mathrm{C}$ and $600^{\circ} \mathrm{C}$ 
are similar to those obtained by cold rolling, both in orientations and intensity. The deformation temperature does not seem to perturb the rotations that lead to textural definition even for $40 \%$ reduction. On the other hand, the recrystallisation textures seem to be better defined for the $60 \%$ reduced materials. Again, the $60 \%$ warm rolled and recrystallysed ODF is similar to that resulting from cold rolling and annealing. The predicted formability parameters are well within the expected values for this type of sheet steel. These results indicate that a continuous rolling processing down to lower temperatures is feasible, for IF steels, capable of yielding a material with acceptable forming properties.

\section{Acknowledgements}

The authors would like to thank the National Steel Company (CSN) for supplying the testing material and the National Research Council (CNPq) for the financial support.

\section{References}

Ávila, N. V. V. (1998) Influence of Hot Rolling Conditions on Texture and Mechanical Properties of an IF Steel, Ph.D. Thesis, IME, Rio de Janeiro, Brazil.

Barnett, M. R. (1996) Influence of Warm Rolling Temperature on Ferrite Recrystallization in Low C and IF Steels, Ph.D. Thesis, McGill University.

Barnett, M. R. and Jonas, J. J. (1997) ISIJ International, 37, 697.

Bunge, H. J. (1965) Z. Metallkunde, 56, 872.

Daniel, D. and Jonas, J. J. (1990) Met. Trans., 31A, 331.

Harlet, P., Beco, F., Cantinieaux, P., Bouquegneau, D., Messien, P. and Herman, J. C. (1993) Int. Symp. on Low C Steels for the 90's, Eds., Asfahani, R. and Tither, G. TMS, Warrendale, 389.

Matheus, J. R. G. (1999) Warm Rolling Textures in IF Steels, M.Sc. Thesis, IME, Rio de Janeiro. 